\title{
PENERAPAN ACTIONSCRIPT \\ PADA ADOBE PHOTOSHOP
}

\author{
Jenisa Felisa \\ Sekolah Tinggi Manajemen Informatika dan Komputer LIKMI \\ Jl. Ir. H. Juanda no 96 Bandung \\ jenisafelisa@gmail.com
}

\begin{abstract}
ABSTRAK
Fasilitas Actionscript dalam Adobe Photoshop adalah serangkaian perintah yang terekam dan dapat dijalankan kapanpun oleh penggunanya. Penggunaan atau manipulasi Actions akan memerintahkan Adobe Photoshop untuk mengerjakan suatu task secara otomatis sehingga pengguna tidak perlu mengerjakan task tersebut secara manual dan proses pengerjaannya akan dieksekusi dengan lebih cepat. Adobe Photoshop menyediakan fasilitas untuk merekam serangkaian actions tersebut dan dapat memanipulasinya sebagai sebuah set yang dapat dipakai beeulang kali setiap pengguna menjalankan event tertentu.
\end{abstract}

Kata kunci : Actions, Task, Adobe Photoshop, Actionscript.

\section{PENDAHULUAN}

Adobe Photoshop merupakan salah satu perangkat lunak yang paling populer digunakan dikalangan profesional maupun orang awan untuk keperluan pengolahan gambar. Hal ini dapat disebabkan karena Adobe Photoshop merupakan sebuah perangkat lunak yang bernaung dalam paket perangkat lunak Design Adobe sehingga fleksibel untuk digunakan dengan perangkat lunak lainnya seperti Adobe Illustrator, Adobe Dreamweaver, Adobe Flash, Adobe After Effect dan perangkat lunak Adobe Master Collection lainnya. Adobe Photoshop juga memiliki tampilan antar muka yang interaktif dan mudah untuk digunakan bahkan untuk para pemula.

Pengolahan gambar pada Adobe Photoshop dapat digunakan sesuai dengan keperluan penggunanya, sehingga untuk benar-benar menyesuaikan Adobe Photoshop menyediakan fitur untuk melalukan custom penggunaan dengan set. Set dalam Adobe Photoshop merupakan sebuah folder berisi sekumpulan perintah (actions) yang diberikan kepada perangkat lunak untuk melakukan suatu tugas (task) atau lebih atau juga biasa disebut dengan Actionscript. Penggunaan atau manipulasi Actionscript akan memerintahkan Adobe Photoshop untuk mengerjakan serangkaian task secara otomatis sehingga pengguna tidak perlu mengerjakan task tersebut secara manual dan proses pengerjaannya akan dieksekusi dengan lebih cepat.

Adobe Photoshop menyediakan layanan untuk merekam aktivitas penggunaan proses editing gambar ke dalam sebuah set Actionscript, sehingga ketika serangkaian Actions sudah terekam, pengguna dapat memakai serangkaian action tersebut pada gambar atau dokumen lainnya secara berulang-ulang. 


\section{PEREKAMAN ACTIONSCRIPT DALAM ADOBE PHOTOSHOP}

Fasilitas Actionscript dalam Adobe Photoshop adalah serangkaian perintah yang terekam dan dapat dijalankan kapanpun oleh penggunanya. Untuk memulai perekaman Actionscript, pengguna dapat melakukan langkah-langkah berikut ini :

a. Buka menu "Window" dan pilih sub menu "Actions", maka panel Action akan muncul biasanya pada bagian kanan lembar kerja.

b. Dalam panel "Actions" akan ada beberapa tombol yang dapat digunakan.

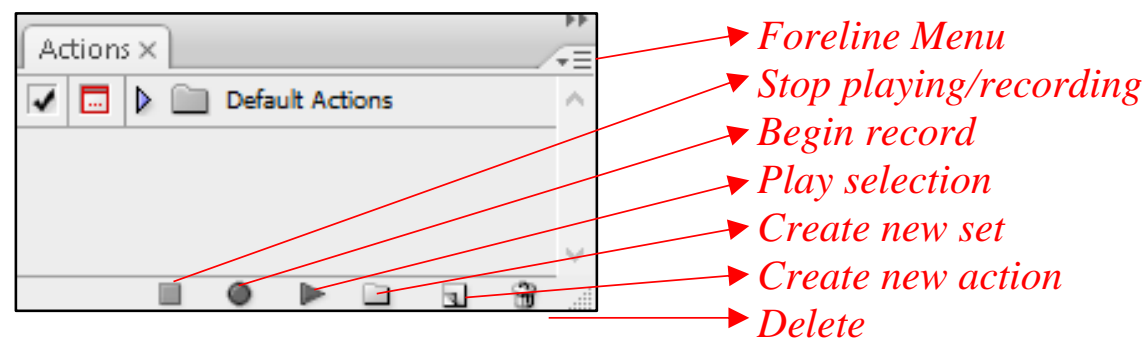

Gambar 1

Panel "Actions"

c. Sebelum muai merekam, sebaiknya pengguna membuat sebuah set baru dengan klik tombol "Create New Set", lalu mengisi nama set (set adalah folder untuk sekumpulan action). Hal ini dilakukan agar action yang terekam tidak bercampur dengan Default Actions.

d. Untuk memulai proses perekaman Actionscript, klik tombol "Begin Record", lalu pengguna dapat mengerjakan proses editing seperti biasa dan memantau action-action yang terekam.

e. Untuk menghentikan proses perekaman, klik tombol "Stop recording".

f. Jika pengguna hendak menyisipkan action tertentu, melanjutkan proses perekaman, atau menghentikan kembali proses perekaman, pengguna dapat menekan tombol "Begin Record" dan "Stop Recording" kembali.

g. Jika pengguna hendak mengecek proses pengerjaan Action, pengguna dapat menekan tombol "Play Action"

h. Jika pengguna hendak menghapus proses dalam urutan action, pilih action yang hendak dihapus, lalu klik "Delete Action".

Jika terdapat perintah yang tidak terekam secara otomatis dalam proses perekaman Actionscript, contohnya seperti perintah perubahan view lembar kerja, maka pengguna harus memasukkan perintah tersebut kedalam daftar rekaman dengan langkah berikut :

a. Pilih set yang akan disisipkan Action, klik "FrontLine Menu" pada panel Actions

b. Pilih dan klik submenu "Insert Menu Items"

c. Akan muncul kotak dialog insert menu items

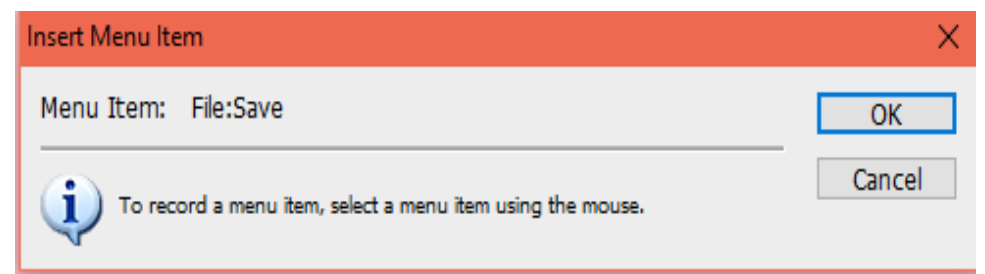

Gambar 2

Panel "Insert Menu Item" 
Saat kotak dialog tersebut masih dalam keadaan aktif, masukkan perintah yang sebelumnya tidak terekam dalam set, contohnya pilih menu "View", lalu klik submenu "Screen Mode", lalu klik submenu "Full Screen Mode" untuk memasukkan perintah pengubahan tampilan lembar kerja menjadi full screen.

\section{IMPLEMENTASI ACTIONSCRIPT PADA ADOBE PHOTOSHOP}

Setelah perintah-perintah terekam dalam sebuah set, maka pengguna dapat menggunakan set tersebut menjadi serangkaian perintah yang akan otomatis dijalankan oleh Adobe Photoshop dalam kondisi tertentu, seperti saat membuka dokumen baru, membuka gambar, menyimpan file dan kondisi lainnya. Implementasi Actionscript dapat dilakukan dengan beberapa cara, yang pertama dengan menggunakan tombol play, lalu cara lainnya adalah dengan menggunakan fasilitas Script Events Manager.

Berikut merupakan langkah penerapan dengan tombol play:

a. Buka sebuah dokumen baru atau gambar baru, lalu tampilkan panel "Actions" dengan klik menu "View", lalu klik submenu "Actions"

b. Pilih set yang sudah disimpan sebelumnya lalu klik tombol "Play" pada panel "Actions" Berikut merupakan langkah penerapan dengan Script Events Manager :

a. Pilih menu "File", lalu klik submenu "Script", lalu klik submenu "Script Event Manager"

b. Akan muncul panel "Script Events Manager",

1) Pilih "Enable Events to Run Scripts/Actions"

2) Pada bagian Photoshop Event, pilih event yang akan digunakan pengguna untuk menjalankan set yang sudah disimpan secara otomatis kedepannya

3) Untuk menyisipkan skrip mentah pengguna dapat memilih menu "Script", Adobe Photoshop mengeksekusi dokumen skrip dengan format AppleScript, JavaScript, VisualBasicScript. Sedangkan untuk mengeksekusi sang sudah disimpan dan pilih action pertama yang harus dijalankan saat Adobe Photoshop melakukan event yang sudah dipilih.

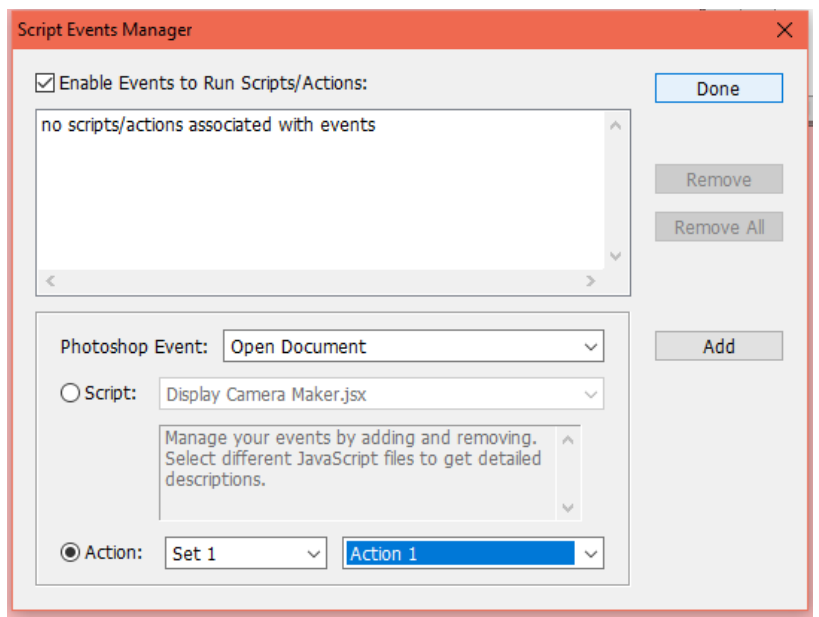

Gambar 3

Panel "Script Events Manager"

4) Klik "Done" untuk menerapkan set Actionscripts. Jika pengguna hendak menghapus Action atau Script, maka klik tombol "Remove" atau "Remove All". Jika pengguna hendak menambahkan Action aau Script, maka klik tombol "Add". 
Pada gambar 3 dicontohkan bahwa pengguna hendak menjalankan Actionscript pada "Set 1" yang dimulai dari "Action 1" secara otomatis setiap pengguna membuka dokumen atau gambar baru.

\section{KESIMPULAN}

Perangkat lunak Adobe Photoshop memiliki fasilitas yang dapat memudahkan penggunannya untuk menjalankan serangkaian task secara otomatis dan sifatnya repetitif (dapat digunakan berulang kali) sehingga akan memudahkan dam mempercepat pengguna untuk melakukan pekerjaan editing gambar.

\section{DAFTAR PUSTAKA}

[1] Adobe.com, "Adobe Photoshop Scripting”, https://www.adobe.com/devnet/ photoshop/scripting.html, diakses pada tanggal 2 Mei 2020 pukul 15.00.

[2] 2007, Adobe Photoshop CS3 Scripting Guide, Adobe Systems Incorporated, USA. 